OPEN ACCESS

Edited by:

Yue Geng,

Ministry of Agriculture and Rural

Affairs, China

Reviewed by:

Xiangwei Wu,

Anhui Agricultural University, China

Xuesheng $\mathrm{Li}$,

Guangxi University, China

*Correspondence:

Pengqiang Du

dupengq@163.com

Lin Zhou

zhoulinhenau@163.com

Yongquan Zheng

zhengyongquan@ippcaas.cn

Specialty section:

This article was submitted to

Toxicology, Pollution and the

Environment,

a section of the journal

Frontiers in Environmental Science

Received: 12 November 2021

Accepted: 14 February 2022

Published: 04 March 2022

Citation:

Li S, Du P, Wu X, He H, Zhou L,

Dong F, Liu X and Zheng Y (2022)

Trifluralin Impacts Soil Microbial

Community and Functions.

Front. Environ. Sci. 10:813871.

doi: 10.3389/fenvs.2022.813871

\section{Trifluralin Impacts Soil Microbial Community and Functions}

\author{
Shuang $\mathrm{Li}^{1}$, Pengqiang $\mathrm{Du}^{1 *}$, Xiaohu $\mathrm{Wu}^{2}$, Hairong $\mathrm{He}^{3}$, Lin Zhou ${ }^{1 *}$, Fengshou Dong ${ }^{2}$, \\ Xingang Liu $^{2}$ and Yongquan Zheng ${ }^{2 *}$
}

${ }^{1}$ College of Plant Protection, Henan Agricultural University, Zhengzhou, China, ${ }^{2}$ State Key Laboratory for Biology of Plant Diseases and Insect Pests, Institute of Plant Protection, Chinese Academy of Agricultural Sciences, Beijing, China, ${ }^{3}$ College of Pharmacy, Henan University of Chinese Medicine, Zhengzhou, China

A 3-month experiment was designed to research the impact of trifluralin (TFL) on soil microbial communities and functions under the condition of greenhouse. In this work, silty loam from Langfang was treated with three doses of $\operatorname{TFL}(1,260,12,600$, and $126,000 \mathrm{~g} \mathrm{ha}^{-1}$ ) and incubated for 90 days. The half-lives of TFL were 15-23 days in all cases. The bacterial and fungal diversities and community structures were impacted by TFL. The bacterial functions of chemoheterotrophy and sulfur oxidation were decreased shortly, but the hydrocarbon degradation ability was significantly increased in the results of functional annotation of prokaryotic taxa (FAPROTAX). For the predicted results of Tax4Fun, amino acid (arginine and proline) metabolism and ABC transporter were decreased significantly, while nitrogen metabolism and ribosome translation were significantly increased. In conclusion, this work aids us to understand the risk of TFL in soil more comprehensively.

Keywords: trifluralin, soil microbe, community structure, bacterial function, fungal function

\section{INTRODUCTION}

Trifluralin (TFL, 2,6-dinitro-N, N-di-n-propyl-4-trifluoromethylaniline) is a fluorine-containing selective pre-emergence dinitroaniline herbicide, which is mainly used to control monocotyledonous weeds and annual broadleaf weeds, such as barnyard grass, Eragrostis cilianensis, crabgrass, setaria, and goosegrass (Nyporko et al., 2002; Zhu and Chen, 2003; Soltani et al., 2010; Perez-Moreno et al., 2014). It is an important herbicide in China, and there are 167 products that have been registered by 2021. The herbicidal mechanism of TFL is to inhibit the polymerization of tubulin and tissue development, inhibit meristem cell division, destroy cells, and inhibit photosynthesis to make weeds die (Nyporko et al., 2002; Chen et al., 2021). According to the research of Bansal (2011), most pesticides will get into the soil, especially for herbicides. TFL showed a long half-life in soil (Triantafyllidis et al., 2010; Du et al., 2018; Lu et al., 2019), and that was potentially harmful to soil life (Bezchlebová et al., 2007; Merlini et al., 2012; Wang et al., 2016).

Soil harbors thousands of microorganisms. They are the fundamental of soil functions and ecosystem balance, for example, maintaining plant growth and reproduction, removing harmful pollution, protecting groundwater, and fixing carbon (Zhao, 2008; Shu et al., 2016). However, the influenced soil microorganisms and impacted soil functions by pesticide have been proven by some researchers (Ju et al., 2016; Du et al., 2018; Fang et al., 2020). In the study by Ju, under the stress of myclobutanil, the abundance of bacteria, fungi, N-related gene (nifH and amoA), soil basal respiration, and microbial biomass carbon were impacted (Ju et al., 2016). Fang et al. (2020) reported that chloropicrin influenced bacterial abundance, community structure, and soil functions. In addition, in the study of Du et al. (2018), the authors reported that TFL influenced the biomass and 


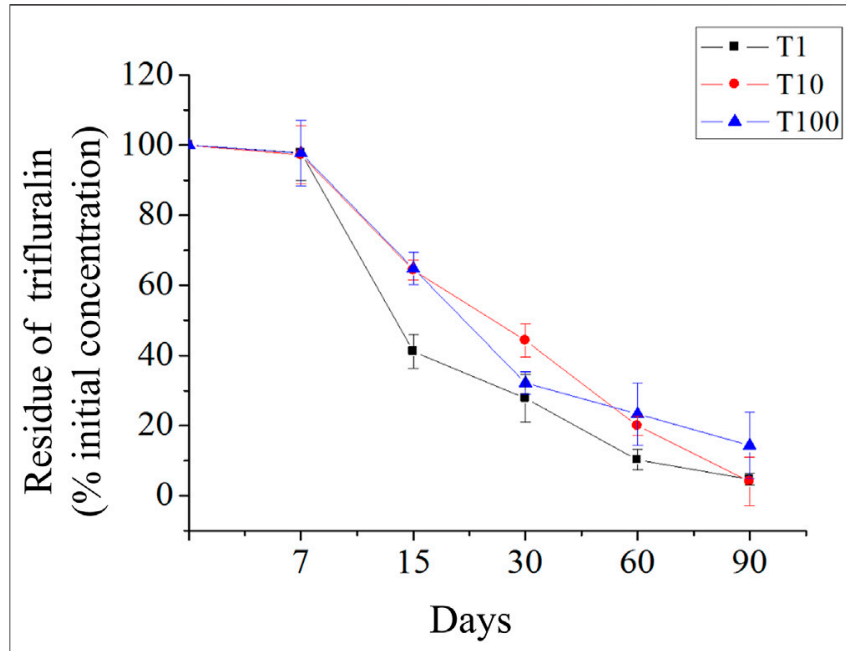

FIGURE 1 | Dynamics of trifluralin degradation in soil. The concentration of trifluralin is expressed as the \% of the initial concentration for sampling date.

the ecology of soil microorganisms, and the $\mathrm{N}$ cycling is also influenced. However, the previous research of Du et al. (2018) was limited as it was an indoor experiment without plants and the functions only focused on $\mathrm{N}$ cycling.

Thus, in order to get close to the actual situation and better understand the impact on soil ecology and functions, we designed a 3-month experiment in greenhouse to evaluate the impact of TFL on bacterial and fungal ecotoxicology and the related functions. The focuses of this work were to evaluate the following questions: 1) the impact of TFL on the soil microbial community structure and 2) evaluate the influence on soil functions in greenhouse. This work can help us to deeply understand the impact of TFL on soil microbiome and their functions in greenhouse.

\section{MATERIALS AND METHODS}

\section{Soil, Experimental Design, and Sample Collection}

The soil was collected from the Langfang experimental site of the Chinese Academy of Agricultural Sciences and classified as silty loam according to the particle size of each soil. The soil was filtered by a 2-mm sieve, and the physical and chemical properties of the soil were $18 \mathrm{~g}$ of organic matter $\mathrm{kg}^{-1}, 74.9 \mathrm{mg}$ of available phosphorus $\mathrm{kg}^{-1}$, an electric conductivity of $95.8 \mathrm{us} \mathrm{cm}^{-1}$, and a $\mathrm{pH}$ of 7.07. After that, the soil was placed in a $40 \times 60 \times 20$ plastic basket, and the soil depth was $15 \mathrm{~cm}$. Each basket contained $45 \mathrm{~kg}$ soil. There were some holes at the bottom of the plastic basket, and the diameter of each hole was $1 \mathrm{~cm}$ and the distance between every two holes was $5 \mathrm{~cm}$. The soybean seed used was Zhonghuang 37. In each basket, 10 seeds were planted, and the sowing depth was $3-5 \mathrm{~cm}$. The purity of TFL was $98.4 \%$, which was bought from Beijing Qinchengyixin Technology Development Co., Ltd., (Beijing, China). There were three doses of TFL: T1 was the recommended dose of $1,260 \mathrm{~g} \mathrm{ha}^{-1}$
TABLE 1 | Kinetic parameters of trifluralin degradation in soil at three different concentrations.

\begin{tabular}{lccc} 
Parameters & \multicolumn{3}{c}{ Treatment } \\
\cline { 2 - 4 } & $\mathbf{T 1}$ & $\mathbf{T 1 0}$ & $\mathbf{T 1 0 0}$ \\
$\mathrm{A}$ & 0.838 & 3.43 & 79.15 \\
$k_{1}$ & 0.0467 & 0.0295 & 0.03822 \\
$\mathrm{~B}$ & 0.025 & 0.4052 & 0.1 \\
$k_{2}$ & 0 & 0.0295 & 0 \\
$t_{1 / 2}(\mathrm{~d})$ & 15 & 23 & 21 \\
$r^{2}$ & 0.93 & 0.98 & 0.96
\end{tabular}

Trifluralin degradation in soil was described by bi-exponential kinetic model: $\mathrm{PC}(\mathrm{t})=A \times$ $\exp \left(-\mathrm{k}_{1} \times t\right)+B \times \exp \left(-\mathrm{k}_{2} \times t\right)$, where $P C$ is the concentration at time $t ; A$ and $B$ are constants; and $\mathrm{k}_{1}$ and $\mathrm{k}_{2}$ are the dissipation kinetic constants of the first and second components; $t_{1 / 2}$ is the half-life of the initial trifluralin concentration. $11: 1,260 \mathrm{~g} \mathrm{ha}^{-1}$, T10: $12,600 \mathrm{~g} \mathrm{ha}^{-1}$, T100: 12,600 $\mathrm{g} \mathrm{ha}^{-1}$.

in the field (0.03024 $\mathrm{g}$ for each basket), and T10 and T100 were 10 and 100 times of the recommended dose, respectively. The mother liquor was prepared with $1 \mathrm{ml}$ acetone $(0.03024 \mathrm{~g}$ for each basket for T1, $0.3024 \mathrm{~g}$ for each basket for T10, and $3.024 \mathrm{~g}$ for each basket for T100), and Tween 80 was added according to $0.5 \%$ of the mother liquor volume. After that, mother liquor was sprayed with $500 \mathrm{ml}$ water in a hand-held sprayer. The control treatment has also been prepared and sprayed with $500 \mathrm{ml}$ water. Each treatment was repeated three times. A $3-\mathrm{cm}$ diameter soil sample was used to collect five samples in each plastic basket using a diagonal sampling method at days 7, 15, 30, 60, and 90 . The sampling depth was $0-10 \mathrm{~cm}$. The sampling site in basket was $3 \mathrm{~cm}$ away from the root. A part of each sample was used for the residual analysis of trifluralin, and the rest of the soil was stored at $-80^{\circ} \mathrm{C}$ for DNA analysis.

\section{Trifluralin Extraction and Detection}

The procedure of TFL residue analysis was performed according to Du et al. (2018). Briefly, $5.0 \mathrm{~g}$ soil samples were extracted by $20 \mathrm{ml}$ acetone. The extracted samples were detected by Agilent GC 7890A (Agilent Technologies, Santa Clara, CA, United States) gas chromatography equipped with an electron capture detector. The carrier gas for gas chromatography was helium, and the flow rate was $1 \mathrm{ml} \mathrm{min}^{-1}$; the injection volume was $1 \mu \mathrm{l}$, without the shunt injection; the temperature of the injector was $250^{\circ} \mathrm{C}$, and the initial temperature of the column was $150^{\circ} \mathrm{C}$ for $2 \mathrm{~min}$, then the temperature of $20^{\circ} \mathrm{C} \mathrm{min}{ }^{-1}$ was increased to $280^{\circ} \mathrm{C}$ and held for $2 \mathrm{~min}$. The electron capture detector temperature was $300^{\circ} \mathrm{C}$.

\section{DNA Extraction}

A MoBio PowerSoil DNA Isolation Kit (Mo Bio Laboratories, Carlsbad, CA, United States) was used to extract soil DNA. In total, $1 \%$ agarose gel electrophoresis was used to assess the extraction effect, and the DNA concentrations were measured by NanoDrop 1000 spectrophotometry.

\section{NGS of Bacterial and Fungal Communities}

A GeneAmp 9700 PCR machine (Applied Biosystems, Waltham, MA, United States) was used to amplify the 16S rDNA V3V4 region gene and ITS hypervariable region gene. The pair of primers used for $16 \mathrm{~S}$ rRNA were $341 \mathrm{~F}$ ( $5^{\prime}$-CCTACGGGAGGC 
TABLE 2 | Shannon diversity index of bacteria and fungi in soil with different treatments and days.

\begin{tabular}{|c|c|c|c|c|c|c|}
\hline \multirow[t]{2}{*}{ Diversity } & \multirow[t]{2}{*}{ Dosages } & \multicolumn{5}{|c|}{ Days after application } \\
\hline & & 7 days & 15 days & 30 days & 60 days & 90 days \\
\hline \multirow[t]{4}{*}{ Bacteria } & CK & $6.87 \pm 0.05 a$ & $6.87 \pm 0.09 a$ & $7.05 \pm 0.12 a$ & $7.11 \pm 0.05 a$ & $7.08 \pm 0.06 a$ \\
\hline & $\mathrm{T} 1$ & $6.92 \pm 0.11 a$ & $7.07 \pm 0.03 \mathrm{bc}$ & $7.04 \pm 0.13 a$ & $7.12 \pm 0.01 a$ & $7.04 \pm 0.10 a$ \\
\hline & $\mathrm{T} 10$ & $6.98 \pm 0.05 a$ & $6.99 \pm 0.050 b$ & $7.07 \pm 0.08 a$ & $7.09 \pm 0.01 a$ & $7.00 \pm 0.06 a$ \\
\hline & T100 & $7.00 \pm 0.02 a$ & $7.12 \pm 0.03 c$ & $7.13 \pm 0.02 a$ & $7.14 \pm 0.03 a$ & $7.00 \pm 0.04 a$ \\
\hline \multirow[t]{4}{*}{ Fungi } & CK & $3.24 \pm 0.11 a$ & $3.26 \pm 0.15 a$ & $3.32 \pm 0.13 a$ & $2.78 \pm 0.85 a$ & $3.21 \pm 0.13 b$ \\
\hline & $\mathrm{T} 1$ & $3.27 \pm 0.11 a$ & $3.33 \pm 0.05 a$ & $3.44 \pm 0.06 a$ & $3.47 \pm 0.18 a$ & $3.53 \pm 0.08 b$ \\
\hline & $\mathrm{T} 10$ & $3.16 \pm 0.29 a$ & $3.26 \pm 0.28 a$ & $3.32 \pm 0.10 a$ & $3.18 \pm 0.11 a$ & $2.49 \pm 0.41 a$ \\
\hline & $\mathrm{T} 100$ & $3.37 \pm 0.08 a$ & $3.41 \pm 0.21 a$ & $3.44 \pm 0.13 a$ & $3.47 \pm 0.10 a$ & $3.50 \pm 0.06 b$ \\
\hline
\end{tabular}

Mean values $(\mathrm{n}=3)$ S.E. Different letters indicate significant difference $(\mathrm{p}<0.05$, Duncan's test).

AGCAG-3 $\left.{ }^{\prime}\right)$ and 806R ( $5^{\prime}$-GGACTACNNGGGTATCTAAT- $\left.{ }^{\prime}\right)$ (Yu et al., 2005), and for the ITS rRNA gene, ITS3_KYO2 (5'GCATCGATGAAGAACGCAGC- $\left.3^{\prime}\right)$ and ITS4 (5'ATATGTAGGATGAAGAACGYAGYRAA-3') (Tian et al., 2017) were used. PCR products were tested by gel electrophoresis and purified using the Qiagen PCR Purification Kit (Qiagen, Hilden, Germany). Then, a Qubit 3.0 fluorometer was used to determine the concentration of PCR products. At last, Illumina HiSeq 4000 (Santiago, CA, United States of America) was used to sequence the qualified library, and the reading length was PE250.

\section{Bioinformatics}

Quantitative analysis of microbial ecology was used to operate procedures to process raw reads. The following rules were used to filter raw reads: the reads with $>10 \%$ unknown nucleotides or $<80 \%$ of the total number of nucleotides with the mass value $>20$ were removed. According to the overlapping relationship, the filtered reads were spliced into tags according to $>10 \mathrm{bp}$ overlapping and $<2 \%$ mismatch rate. After removing the chimeric sequences, the reads of each sample were flattened, and then the sequences with similarity $\geq 97 \%$ were clustered into the same operational taxon by UPARSE (Edgar, 2013). The representative sequences of each operational taxon were selected and compared with the RDP database for species annotation. The Shannon Weiner index was used to calculate diversity. The Bray-Curtis distance was used to visualize beta diversity differences using principal component analysis (PCoA). Functions which related to the metabolism have been predicted by Tax4Fun (Aßhauer et al., 2015). Functional annotation of prokaryotic taxa (FAPROTAX) has been used to evaluate the impact on element cycling (Louca et al., 2016). FUNGuild has been used to predict the functions of fungi (Nguyen et al., 2016).

\section{Data Analyses}

One-way ANOVA and correlation analysis of the diversity of bacteria and fungi were performed using SAS statistical software version 9.2 (SAS Institute Inc., Cary, NC, United States). The significant differences of bacterial and fungal diversities between different treatments were tested using Fisher's least significant difference test, and a $5 \%$ level was set $(p<0.05)$. The $\alpha$ diversity index was used to represent the diversity of bacteria and fungi in soil.

\section{RESULTS}

\section{TFL Degradation}

The degradation dynamics of TFL in the soil was described by a bi-exponential kinetic model: $P C(t)=\mathrm{A} \times \exp \left(-k_{1} \times \mathrm{t}\right)+\mathrm{B} \times$ $\exp \left(-k_{2} \times \mathrm{t}\right)$, where $\mathrm{PC}$ is the concentration at time $\mathrm{t}$; $\mathrm{A}$ and $\mathrm{B}$ are constants; and $k_{1}$ and $k_{2}$ are the dissipation kinetic constants of the first and second components, respectively (Figure 1, Table 1). The initial depositions were $0.80,7.87$, and $81.87 \mathrm{mg} \mathrm{kg}^{-1}$. After incubation, it was reduced to $95.26,95.92$, and $85.62 \%$ for $\mathrm{T} 1$, T10, and T100 treatments, with half-lives of 15, 23, and 21 days, respectively, in greenhouse. It was not detected in the control samples.

\section{Bacterial and Fungal Profiles in Response to TFL}

After quality filtering, we obtained 2,882,931 effective bacterial sequences, and they were clustered into 7,168 bacterial OTUs. The bacterial diversity is shown in Table 2, and it was just significantly increased at day 15 in all TFL treatments. The PCoA plot based on Bray-Curtis distance was used to analyze and compare the bacterial communities at the OTU level (Figure 2A). In the plot, control and $\mathrm{T} 1$ could be separated from others at days 15,30 , and 60 .

After quality filtering, we obtained 4,270,144 effective fungal sequences, and they were clustered into 7,168 fungal OTUs. The fungal diversity is shown in Table 2, and it was slightly increased in T1 and T100 at day 90. The PCoA plot was used to analyze and compare fungal communities at the OTU level (Figure 2B). In the plot, T10 and T100 were separated from other treatments at days 7,15 , and 30.

\section{Impact of the Functions Related to Element Cycling}

The functions of element cycling were predicted by FAPROTAX and are shown in Figure 3. Predatory or exoparasitic was increased in T10 and T100 treatments at day 7, but it was decreased in T1 and T10 treatments at day 60 . Chemoheterotrophy and aerobic chemoheterotrophy were decreased by TFL at day 15, except for chemoheterotrophy in 


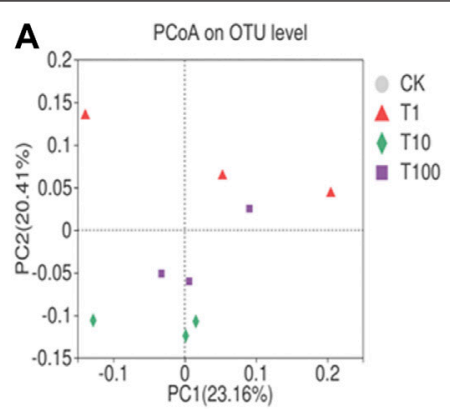

$7 d$

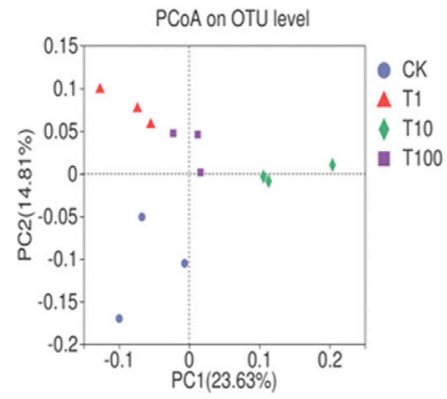

$15 \mathrm{~d}$

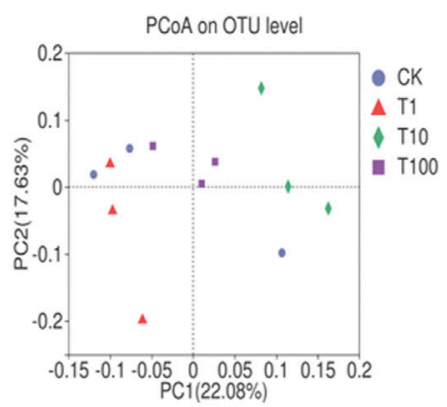

$30 d$

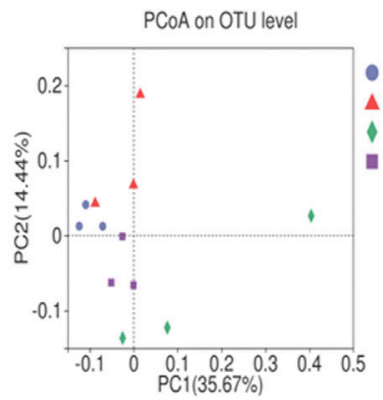

$60 \mathrm{~d}$

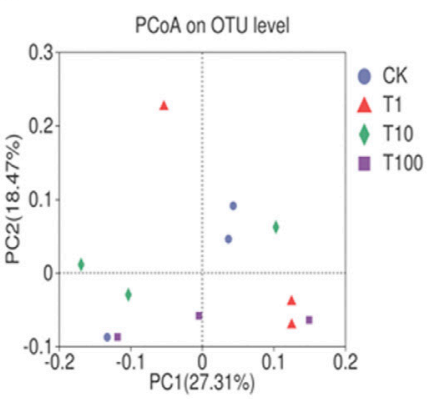

$90 \mathrm{~d}$

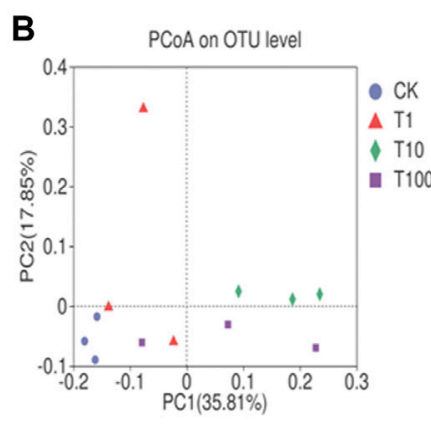

$7 d$

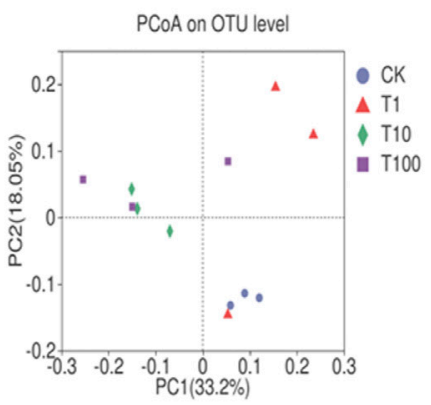

$15 \mathrm{~d}$

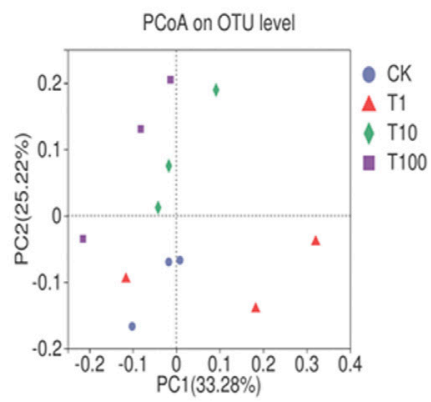

$30 \mathrm{~d}$

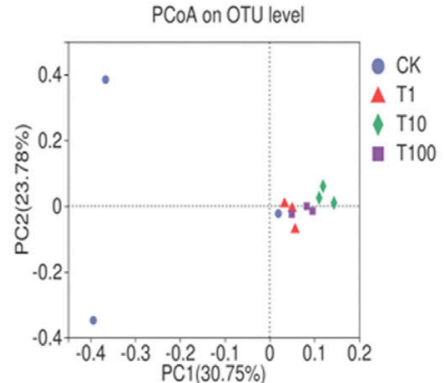

$60 d$

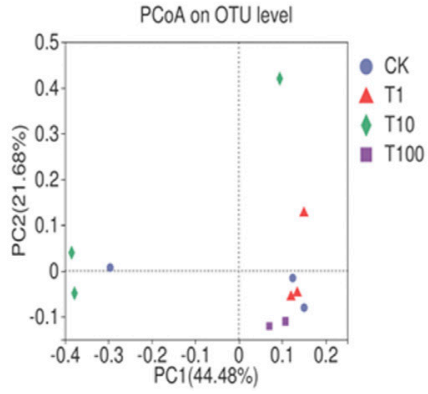

$90 d$

FIGURE 2 | PCoA of bacteria and fungi in soil-based on Bary-Curtis short. (A) is bacteria PCoA, (B) for the fungus PCoA.

T100 treatments. Aliphatic non-methane hydrocarbon degradation was significantly increased in T100 treatment at day 30. Hydrocarbon degradation and aliphatic non-methane hydrocarbon degradation were significantly increased in T100 treatments at day 60 . The dark oxidation of sulfur compounds was decreased in all TFL treatments at day 60. Nitrification and 

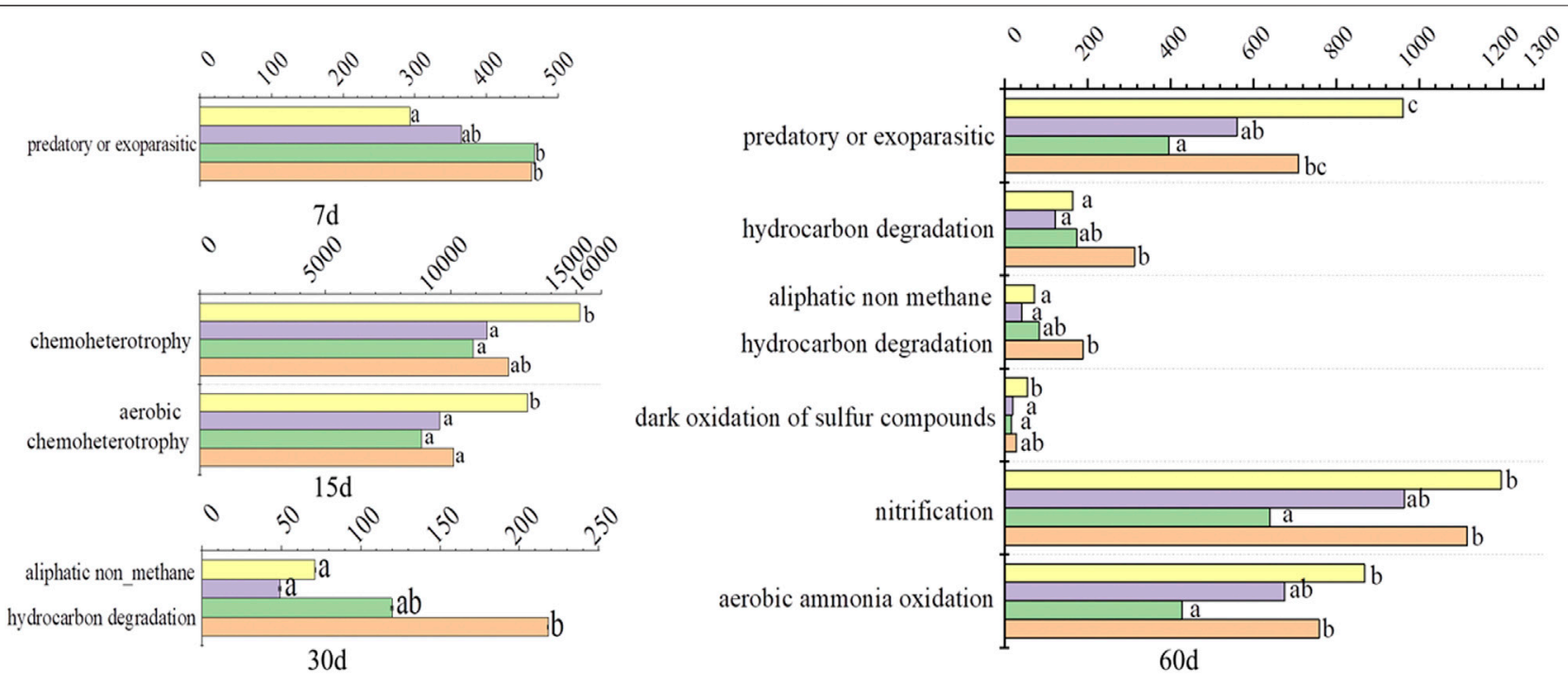

FIGURE 3 | Bacterial functions predicted by FAPROTAX. Letters "a" and "b" on the right of the columns mean significance of difference ( $0<0.05)$.

aerobic ammonia oxidation were significantly decreased in T10 treatment at day 60 .

\section{Effect of Trifluralin on Pathways}

According to the OTU results of $16 \mathrm{~S}$ rRNA sequencing, the Tax4Fun database was used for function prediction analysis. The most abundant 25 pathways are listed in Figure 4. The metabolism of the flagellar assembly was significantly increased from day 30 to day 60 in T10 and T100 treatments, but it was just increased at days 7 and 15 in T10. The ABC transporters, and arginine and proline metabolism were significantly decreased in T10 and T100 from day 7 to day 60, except for $\mathrm{ABC}$ transporters at day 60 . The ribosomal translation was significantly increased from days 7 to 60 in all TFL treatments, except for T1 at day 15. Nitrogen metabolism was increased by TFL from days 30 to 60 . Porphyrin and chlorophyll metabolisms were increased in T100 treatment at day 15, and increased in all TFL treatments at day 60.

\section{Impacted Fungal Functions}

Based on the results of FUNGuild, the influenced functions are shown in Figure 5. The function which related to plant-pathogen was decreased by TFL in T10 and T100 treatments at day 15. Litter saprotroph was just significantly increased in $\mathrm{T} 1$ treatment at day 60 .

\section{DISCUSSION}

Soil microorganisms play an important role in the Earth's ecosystem, such as the mineralization of organic matter, the circulation of organic carbon and nitrogen, and maintaining soil health. In the modern agricultural system, the herbicide is necessary to control herbs. But herbicide influences soil microbiome ecology and soil functions, which has been verified by some researchers (Pampulha et al., 2010; Zabaloy et al., 2012; Petric et al., 2014; Jiang et al., 2019; Jiang et al., 2020; Pertile et al., 2021). TFL is a widely used herbicide for soybean, and Du et al. (2018) have evaluated the impact of TFL on soil ecology and $\mathrm{N}$ cycling. However, there were some limitations, for example, the scale of the experiment was small and they did not evaluate other soil functions. In order to make the data closer to actual agricultural production, we performed this study to evaluate the influence of TFL on soil ecology and functions under greenhouse conditions and planting soybean.

Compared with the previous study (Du et al., 2018), TFL degraded faster in greenhouse. One possible reason was that the greenhouse was a semi-open environment and some TFL has been dissipated by light (Le Person et al., 2007). In addition, there were too much soil in the basket that may induce species in deep soil to communicate with upper soil and promote TFL degradation. The TFL residue in soil in greenhouse also had impact on soil ecology and functions. The increased bacterial diversity suggested that the responses of TFL to diverse species were different. However, this result was opposite from the findings in the indoor experiment of Du et al. (2018), and the most possible reason may be due to the bigger scale of the experiment and higher biological communication. The increased effect of bacterial diversity was also detected in soils contaminated with thiamethoxam (Wu et al., 2020). In addition, the influenced bacterial diversity indicated that bacterial ecology has been seriously disturbed. Therefore, the soil functions were also impacted, which have been proven in this study. The effect of various species to pesticides is different, and it has been proven by Forlani et al. (1995). The changed bacterial community structures in this work were the indirect reflections of different effects of bacterial species on TFL. Similarly, Du et al. (2021) also reported that bacterial diversity and community were influenced by mesosulfuron-methyl in the indoor experiments. Furthermore, the influenced bacterial diversity and community were also 


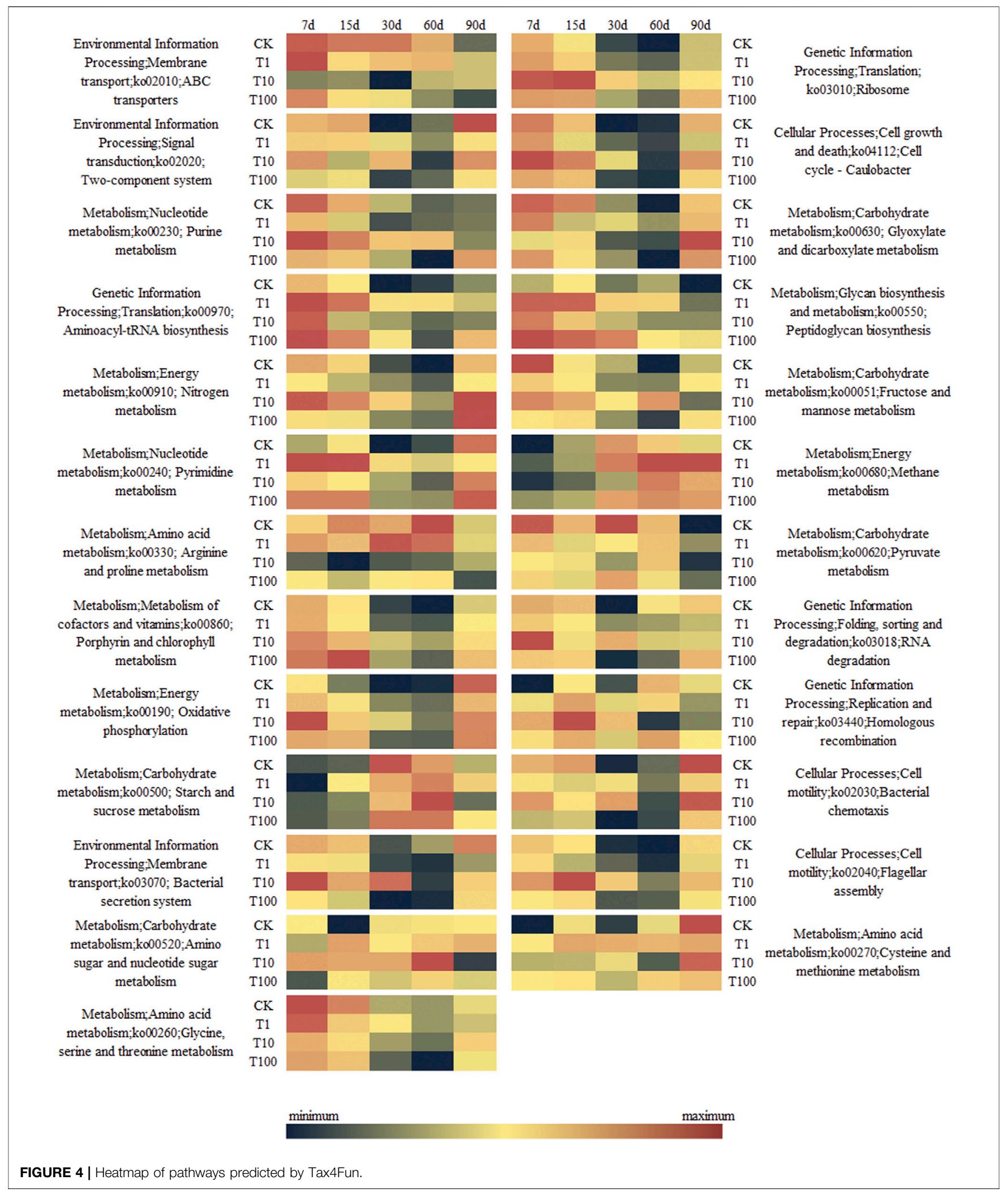




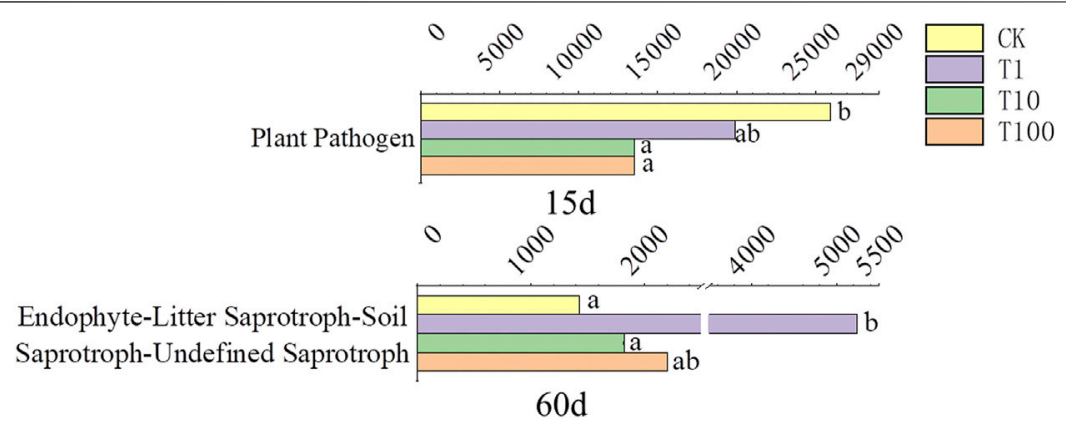

FIGURE 5 | Fungal functions predicted by FUNGuild. Letters "a" and "b" on the right of the columns mean significance of difference ( $p<0.05)$.

observed in the studies of Herath et al. (2017). In addition to its direct effect on bacteria, TFL significantly decreased the diversity of fungi in T10 treatments that coincide with the results of the indoor experiment (Du et al., 2018). Clomazone also showed a decreased effect on the fungal diversity (Wu et al., 2020). The influenced fungal diversity also implied that the ecology and functions of fungi have been impacted. Compared with the fungal PCoA plot in the indoor experiments, the fungal community was slightly influenced, which suggested that the fungal community was more sensitive to TFL in the pot experiments.

Soil microbiota, the base of soil functions, is important in substance and energy exchange, ecological equilibrium maintains, soil fertility increase, and plant growth promotion (Wächtershäuser, 1990; Wardle et al., 2004; Falkowski et al., 2008; Lehtovirta-Morley et al., 2011). The influenced soil microbial ecology in this study suggested that soil functions were influenced. FAPROTAX and Tax4Fun were used to evaluate the functions which were mediated by bacteria. For the results of FAPROTAX, the hydrocarbon degradation ability was the most influenced ability. The aliphatic non-methane hydrocarbon and hydrocarbon degradation pathways were increased, suggesting that the related bacteria were acclimated by TFL and increased the hydrocarbon degradation ability. For the results of Tax4Fun, the $\mathrm{ABC}$ transporters decreased, suggesting that the ability of transmembrane transport was inhibited by TFL, which will influence most metabolism. In addition, the influenced amino acid (arginine and proline) and nitrogen metabolism suggested that $\mathrm{N}$ cycling has been influenced. The influenced fungal functions of saprotroph suggested that the decomposition process of soil has been influenced.

\section{REFERENCES}

Aßhauer, K. P., Wemheuer, B., Daniel, R., and Meinicke, P. (2015). Tax4Fun: Tax4Fun: Predicting Functional Profiles from Metagenomic 16S rRNA Data. Bioinformatics 31, 2882-2884. doi:10.1093/bioinformatics/btv287

Bansal, O. P. (2011). Fate of Pesticides in the Environment. J. Indian Chem. Soc. 88 (10), 1525-1532. doi:10.1016/j.fct.2018.01.034

Bezchlebová, J., Černohlávková, J., Lána, J., Sochová, I., Kobetičová, K., and Hofman, J. (2007). Effects of Toxaphene on Soil Organisms. Ecotoxicology Environ. Saf. 68 (3), 326-334. doi:10.1016/j.ecoenv.2007.05.009

\section{CONCLUSION}

This study performed a pot experiment to explore the effect of TFL on soil microbial ecology and functions. In general, under the treatment of TFL, the bacterial diversity was increased and the fungal diversity was decreased. The bacterial and fungal communities were slightly influenced. Soil functions about hydrocarbon degradation, transmembrane transport, amino acid metabolism, and ribosomal translation were also influenced after TFL exposure. In addition, microbiome connections are also influenced by TFL. Therefore, TFL also showed influence on soil ecology and functions in the pot experiments.

\section{DATA AVAILABILITY STATEMENT}

The raw data supporting the conclusions of this article will be made available by the authors, without undue reservation.

\section{AUTHOR CONTRIBUTIONS}

SL: conceptualization and writing-original draft. PD: methodology, data curation, and writing-review and editing. XW: conceptualization and methodology. $\mathrm{HH}$ : formal analysis and writing-review and editing. LZ: supervision and writing-review and editing. FD: writing-original draft and data curation. XL: supervision. YZ: supervision, writing-review and editing, and supervision.

Chen, J., Yu, Q., Patterson, E., Sayer, C., and Powles, S. (2021). Dinitroaniline Herbicide Resistance and Mechanisms in Weeds. Front. Plant Sci. 12, 634018. doi:10.3389/fpls.2021.634018

Du, P., He, H., Wu, X., Xu, J., Dong, F., Liu, X., et al. (2021). Mesosulfuron-methyl Influenced Biodegradability Potential and $\mathrm{N}$ Transformation of Soil. J. Hazard. Mater. 416, 125770. doi:10.1016/j.jhazmat.2021.125770

Du, P., Wu, X., Xu, J., Dong, F., Liu, X., and Zheng, Y. (2018). Effects of Trifluralin on the Soil Microbial Community and Functional Groups Involved in Nitrogen Cycling. J. Hazard. Mater. 353, 204-213. doi:10.1016/j.jhazmat.2018.04.012

Edgar, R. C. (2013). UPARSE: Highly Accurate OTU Sequences from Microbial Amplicon Reads. Nat. Methods 10 (10), 996-998. doi:10.1038/nmeth.2604 
Falkowski, P. G., Fenchel, T., and Delong, E. F. (2008). The Microbial Engines that Drive Earth's Biogeochemical Cycles. Science 320 (5879), 1034-1039. doi:10. $1126 /$ science. 1153213

Fang, W., Song, Z., Tao, S., Zhang, D., Huang, B., Ren, L., et al. (2020). Biochar Mitigates the Negative Effect of Chloropicrin Fumigation on Beneficial Soil Microorganisms. Sci. Total Environ. 738, 139880. doi:10.1016/j.scitotenv.2020. 139880

Forlani, G., Mantelli, M., Branzoni, M., Nielsen, E., and Favilli, F. (1995). Differential Sensitivity of Plant-Associated Bacteria to Sulfonylurea and Imidazolinone Herbicides. Plant Soil 176 (2), 243-253. doi:10.1007/ BF00011788

Herath, H. M. L. I., Moldrup, P., Jonge, L. W. d., Nicolaisen, M., Norgaard, T., Arthur, E., et al. (2017). Clay-to-Carbon Ratio Controls the Effect of Herbicide Application on Soil Bacterial Richness and Diversity in a Loamy Field. Water Air Soil Pollut. 228, 3. doi:10.1007/s11270-016-3175-6

Jiang, R., Wang, M., Chen, W., Li, X., Balseiro-Romero, M., and Baveye, P. C. (2019). Ecological Risk of Combined Pollution on Soil Ecosystem Functions: Insight from the Functional Sensitivity and Stability. Environ. Pollut. $255(\mathrm{Pt} 1)$, 113184. doi:10.1016/j.envpol.2019.113184

Jiang, R., Wang, M., Chen, W., Li, X., and Balseiro-Romero, M. (2020). Changes in the Integrated Functional Stability of Microbial Community under Chemical Stresses and the Impacting Factors in Field Soils. Ecol. Indicators 110, 105919. doi:10.1016/j.ecolind.2019.105919

Ju, C., Xu, J., Wu, X., Dong, F., Liu, X., and Zheng, Y. (2016). Effects of Myclobutanil on Soil Microbial Biomass, Respiration, and Soil Nitrogen Transformations. Environ. Pollut. 208, 811-820. doi:10.1016/j.envpol.2015. 11.003

Le Person, A., Mellouki, A., Muñoz, A., Borras, E., Martin-Reviejo, M., and Wirtz, K. (2007). Trifluralin: Photolysis under Sunlight Conditions and Reaction with HO Radicals. Chemosphere 67 (2), 376-383. doi:10.1016/j.chemosphere.2006. 09.023

Lehtovirta-Morley, L. E., Stoecker, K., Vilcinskas, A., Prosser, J. I., and Nicol, G. W. (2011). Cultivation of an Obligate Acidophilic Ammonia Oxidizer from a Nitrifying Acid Soil. Proc. Natl. Acad. Sci. 108 (38), 15892-15897. doi:10.1073/ pnas. 1107196108

Louca, S., Parfrey, L. W., and Doebeli, M. (2016). Decoupling Function and Taxonomy in the Global Ocean Microbiome. Science 353 (6305), 1272-1277. doi: $10.1126 /$ science.aaf 4507

Lu, W., Li, L., Li, S., and Zhao, N. (2019). Toxicity and Field Efficacy of WaterSoluble Fluraline Nanocrystals on sunflower. Plant Prot. 45 (03), 237-240+248. doi:10.16688/j.zwbh.2018220

Merlini, V. V., Nogarol, L. R., Marin-Morales, M. A., and Fontanetti, C. S. J. M. R. (2012). Toxicity of Trifluralin Herbicide in a Representative of the Edaphic Fauna: Histopathology of the Midgut of Rhinocricus Padbergi (Diplopoda). Microsc. Res. Tech. 75 (10), 1361-1369. doi:10.1002/jemt.22075

Nguyen, N. H., Song, Z., Bates, S. T., Branco, S., Tedersoo, L., Menke, J., et al. (2016). FUNGuild: An Open Annotation Tool for Parsing Fungal Community Datasets by Ecological Guild. Fungal Ecol. 20, 241-248. doi:10.1016/j.funeco. 2015.06.006

Nyporko, A. Y., Yemets, A. I., Klimkina, L. A., and Blume, Y. B. (2002). Sensitivity of Eleusine Indica Callus to Trifluralin and Amiprophosmethyl in Correlation with the Binding of These Compounds to Tubulin. Russ. J. Plant Physiol. 49 (3), 413-418. doi:10.1023/a:1015561523131

Pampulha, M. E., Ferreira, M. A., and Oliveira, A. (2010). Effects of a Phosphinothricin Based Herbicide on Selected Groups of Soil Microorganisms. J. Basic Microbiol. 47 (4), 325-331. doi:10.1002/jobm. 200610274

Perez-Moreno, L., Castaneda-Cabrera, C., Ramos-Tapia, M., and Tafoya-Razo, J. A. (2014). CONTROL QUÍMICO PREEMERGENTE DE LA MALEZA EN TOMATE DE CÁSCARA. Interciencia 39 (6), 422-427. Available at: https://www.interciencia. net/wpcontent/uploads/2017/11/422-c-P\%C3\%89REZMORENO-6.pdf.

Pertile, M., Sousa, R. M. S., Mendes, L. W., Antunes, J. E. L., Oliveira, L. M. d. S., de Araujo, F. F., et al. (2021). Response of Soil Bacterial Communities to the
Application of the Herbicides Imazethapyr and Flumyzin. Eur. J. Soil Biol. 102, 103252. doi:10.1016/j.ejsobi.2020.103252

Petric, I., Friedel, I., Vasileiadis, S., Martin-Laurent, F., Djuric, S., and Bru, D. (2014). A Tiered Assessment Approach Based on Standardized Methods to Estimate the Impact of Nicosulfuron on the Abundance and Function of the Soil Microbial Community. Soil Biol. Biochem. 75, 282-291. doi:10.1016/j. soilbio.2014.04.022

Shu, Q., Gao, Y., Liu, Y., Wang, Y., and Bao, G. (2016). Calculating Ecological Value of Land Use in the Coastal Areas of Jiangsu Province. J. Geo-Information Sci. 18 (6), 787-796. doi:10.3724/SP.J.1047.2016.00787

Soltani, N., Nurse, R. E., Van Eerd, L. L., Vyn, R. J., Shropshire, C., and Sikkema, P. H. (2010). Weed Control, Environmental Impact and Profitability with Trifluralin Plus Reduced Doses of Imazethapyr in Dry Bean. Crop Prot. 29 (4), 364-368. doi:10.1016/j.cropro.2009.07.011

Tian, X., Yang, T., He, J., Chu, Q., Jia, X., and Huang, J. (2017). Fungal Community and Cellulose-Degrading Genes in the Composting Process of Chinese Medicinal Herbal Residues. Bioresour. Techn. 241, 374-383. doi:10.1016/j.biortech.2017.05.116

Triantafyllidis, V., Manos, S., Hela, D., Manos, G., and Konstantinou, I. (2010). Persistence of Trifluralin in Soil of Oilseed Rape fields in Western Greece. Int. J. Environ. Anal. Chem. 90 (3-6), 344-356. doi:10.1080/03067310903094495

Wächtershäuser, G. (1990). Evolution of the First Metabolic Cycles. Proc. Natl. Acad. Sci. 87 (1), 200-204. doi:10.1073/pnas.87.1.200

Wang, Y., Cang, T., Yu, R., Wu, S., Liu, X., Chen, C., et al. (2016). Joint Acute Toxicity of the Herbicide Butachlor and Three Insecticides to the Terrestrial Earthworm, Eisenia fetida. Environ. Sci. Pollut. Res. 23 (12), 11766-11776. doi:10.1007/s11356-016-6347-4

Wardle, D. A., Bardgett, R. D., Klironomos, J. N., Setalä, H., van der Putten, W. H., and Wall, D. H. (2004). Ecological Linkages between Aboveground and Belowground Biota. Science 304 (5677), 1629-1633. doi:10.1126/science.1094875

Wu, C., Wang, Z., Ma, Y., Luo, J., and She, D. (2020). Influence of the Neonicotinoid Insecticide Thiamethoxam on Soil Bacterial Community Composition and Metabolic Function. J. Hazard. Mater. 405, 124275. doi:10.1016/j.jhazmat.2020.124275

Yu, Y., Lee, C., and Hwang, S. (2005). Analysis of Community Structures in Anaerobic Processes Using a Quantitative Real-Time PCR Method. Water Sci. Technol. 52 (1-2), 85-91. doi:10.2166/wst.2005.0502

Zabaloy, M. C., Gómez, E., Garland, J. L., and Gómez, M. A. (2012). Assessment of Microbial Community Function and Structure in Soil Microcosms Exposed to Glyphosate. Appl. Soil Ecol. 61, 333-339. doi:10.1016/j.apsoil.2011.12.004

Zhao, Q. (2008). Improve Understanding of Soil, the Innovative Modern Soil Science. Acta Pedologica Sinica 45 (05), 771-777. doi:10.3321/j.issn:0564-3929. 2008.05.002

Zhu, W., and Chen, C. (2003). Effect of 48\% Fluralin Emulsion Soil Treatment on Control of Grass Weeds. Hubei Agric. Sci. 3, 57-58. doi:10.3969/j.issn.04398114.2003.03.024

Conflict of Interest: The authors declare that the research was conducted in the absence of any commercial or financial relationships that could be construed as a potential conflict of interest.

Publisher's Note: All claims expressed in this article are solely those of the authors and do not necessarily represent those of their affiliated organizations, or those of the publisher, the editors, and the reviewers. Any product that may be evaluated in this article, or claim that may be made by its manufacturer, is not guaranteed or endorsed by the publisher.

Copyright $\odot 2022 \mathrm{Li}, \mathrm{Du}, \mathrm{Wu}, \mathrm{He}, \mathrm{Zhou}$, Dong, Liu and Zheng. This is an openaccess article distributed under the terms of the Creative Commons Attribution License (CC BY). The use, distribution or reproduction in other forums is permitted, provided the original author(s) and the copyright owner(s) are credited and that the original publication in this journal is cited, in accordance with accepted academic practice. No use, distribution or reproduction is permitted which does not comply with these terms. 